\title{
2. THE PEDAGOGIC CONCEPT OF CREATIVE IMAGATION DEVELOPMENT OF STUDENTS-PLASTIC ARTISTS
}

\author{
Daniela Roşca - Ceban, Olimpiada Arbuz-Spatari ${ }^{258}$
}

\begin{abstract}
The concept of educational development in the Republic of Moldova reveals the political, social and economic transformations, triggered in the republic, which impose the necessity of drawing new ways of developing the education in a creative perspective. The specific note of the education is the orientation of the activities towards the student, the revealing of the creative potential of development and organization of the instructiveeducational activity based on strategies of individualization, engaging the divergent thinking.

Key words: Creative imagination of students artists(CISA), concept of creative imagination development, creative potential, creative product
\end{abstract}

\section{Introduction}

As long creation was considered a hereditary privilege acquired by a minority, the school failed to deal specifically with this issue, although it also created special classes for gifted. Besides traditional effort to educate critical thinking, stimulation of fantasy also appears as a major goal. This involves important changes, both in the mentality of teachers and in the methods of education and training.

First of all, the climate must be changed to eliminate the strong cultural and emotional bottlenecks in the past school. Demanded, democratic relations are required between students and teachers. Then, the way of teaching should require participation, the students' initiative by using specific methods. Finally, fantasy must also be appropriately appreciated, along with the solidity of knowledge, rigorous reasoning and critical spirit [1, p. 169]. The result of any mental activity in the creative direction can be considered a creative product.

The creative pedagogical product engages at least the level of inventiveness, located between meaningful creativity (only in the individual sense) and the relevant one (and) at the social level. At this level, there are only a few individuals, namely "the most flexible and responsive to symbolic processing on large spaces "[4]. Education increases their number precisely because of the creativity exercise permanently engaged in the lesson, form mastering class, etc., which requires the educator to constantly adapt to new, unpredictable situations, in a fast-paced mode.

\section{Discussions}

The creative product reflects the complexity of subject-object correlations. correlations committed at educational / didactic level by multiplying the necessary pedagogical correspondence between pedagogical objectives -

\footnotetext{
${ }^{258}$ Lecturer, Doctoral Candidate / Associate Professor PhD, "Ion Creanga" State Pedagogical University from Chişinău, Republic of Moldova, email: olimpiada123@mail.ru
} 
pedagogical contents - teaching strategies - learning - evaluation, specifically directed to the realization of a formative education.

The field of education develops a space and a pedagogical time open to creativity at the individual level (the creativity of the teaching staff, the creativity of the pupil), collectively (the creativity of the teaching staff, creativity of the pupils class, the creativity of the micro group of pupils) and the social (the creativity of the school organization, national, territorial, local) [4].

The concept of education has over time seen multiple operationalizations and extensions. The evolution of educational processes entails taking into account - during reviews, descriptions, explanations, investigations, optimizations and prospecting - their specificity and complexity as well as their systemic character. The new dimensions of the educational ideal converge to the idea that the individual must be prepared not only for accepting change, but also for initiating, continuing and dominating the change[2].

If man is not only a creature but a creator, and naturally every student has a creative potential, we can ask ourselves what can school and university do not to prevent this potential, but rather to activate, stimulate, develop it, knowing that education has the most non-creative practices. The education system has a pronounced inertial character and carries within it the premises of a conformist and routine attitude.

The educator / teacher / professor can easily remain in a routine approach of the teaching process, content with applying "good" arts education curriculum, incorporating the same themes and ways of learning, etc., notwithstanding that there are other students, that more exciting, stimulating, and creative approaches are possible. Teacher can become the key factor in stimulating the creative spirit of students if:

- starts in the didactic approach from an essentially positive view on human nature;

- considers that it is perfectly normal for someone to feel involved in a decision on which wording was taken;

- believes in students' self-realization capacity and encourages them to do so;

- appreciates individuality, personality;

- encourages, promotes and rewards creativity;

- is engaged in a process of permanent change and has the necessary skills to manage change;

- focuses more on internal motivation than on external motivation;

- focuses on the process and not on the product, what happens to the mental structures involved in learning, and not on the object products (the plastic works itself) [3].

But what can actually be done to stimulate creative imagination? Creative imagination is one of the capabilities that plays an essential role in shaping the entire curriculum at every age and stage. People are born with a natural ability to be curious and interested in their environment. Our ability to imagine a different world and create new possibilities takes us away from other creatures. This 
ability contributes to all aspects of human life and is essential more than ever in the 21st Century, the century that is changing rapidly.

And yet, with the obedience to the increasingly demanding standards of the league classes,examinations, degrees and levels of progress; however, the emphasis should be placed on the content of educational programs that can foster the development of creative imagination. Here we share some of the key messages in the ICSAP development course.

The essential skills of creative imagination

The question and the challenge

• The question "Why?" "How?" "So what?"

- Answering ideas, questions, tasks or problems in an unusual way

- Granting unanswered questions

- Challenges and establishment of common denominators

- Independent thinking

Making Connections and Establishing Relationships

- Recognizing previous meanings, knowledge or experiences

- Generalization of information and experiences, search for trends and models

- Using analogies and metaphors

- Reinterpreting and applying knowledge in new contexts

- Communicating ideas in new or unexpected ways

Assuming what could be

- Imagination and viewing things with eyes closed

- The question, "What if?"

- Viewing alternatives

- Viewing possibilities, problems and challenges

- Looking at and thinking about things differently and from different points of view

Exploring ideas and maintaining open options

- Playing with ideas and experimenting.

- The answer to intuition and trust.

- Keeping an open mind, adapting and changing ideas to get creative results

- Trying for alternatives and fresh approaches

- Anticipating and overcoming difficulties through novel ideas

Critical reflection on ideas, actions and results

- Revision of progress

- Call to feedback

- Making perceptual observations about originality and value

- The question "Is it good is what is necessary?"

- Introducing constructive comments, ideas, explanations and ways to do things.

The challenge for us as teachers is to look at the pedagogical practice and the opportunities around us with a new perspective so that we can start actively encouraging the development of creative imagination.

Creative teaching: involves adapting to innovative approaches in the teaching process to become more exciting or challenging. A demonstration 
lesson to inspire students? Presented as if you were filming for a TV show? A new treatment in the teaching-learning process.

Teaching Creative Learning: involves giving students autonomy; so that students make the most of the work - thinking, research, elaboration.

Environment: Contingency and Learning Analysis. There are ways to help students, create spaces to encourage curiosity and stimulate creative imagination.

Resources: There are materials that are cheap or free to use and adapt to encourage students to invent and adapt, encouraging students to find their own affordable, inexpensive or free materials to mold and make their own creations. Having good ideas, putting creative imagination in function, planning and doing things to happen, we discover a series of capabilities that are essential in a world where the pace of change requires adaptability, resilience, and risk-taking. Knowledge alone is not enough.

Very young children have the natural curiosity to explore and experience, but sometimes formal institutions put barriers around them and learn that there is a fair and wrong answer to everything. Certainly, we want our students to remove barriers and appeal to their creative imagination as often as possible. And the first stage in this process at the higher level of studies is the development of creative imagination in the classroom. The Foundamentals of Decorative Arts course at the level of creative imagination will allow:

- Planning the projects, lessons and challenges that promote creative thinking in the learning process.

- Linking creative approaches to real-world challenges.

- Understanding the issues involved in evaluating creativity and making an objective assessment.

- Collaborating, planning and leading professional development through reflective practices

- Learning strategies to consciously develop creative imagination.

It is hard to imagine another human feature that has had a profound positive effect on the world than creative imagination. This psychic element has generated so many admirable things. It is individual and universal, intellectual and well understood, born of inspiration and determination. Particularly human, but often misunderstood, creative imagination is fundamental to life. Here are some principles on which creative imagination is based.

Everyone possesses creative imagination

Forget titles, job descriptions, and hierarchy - Creative imagination does not imply a set of skills, it is a mentality, an orientation that resists ordinary thinking and invites to courageous explorations. Being human is to be creative.

Creative imagination is paradoxical

Contradictions of creative imagination contribute to the mystery that surrounds it. Creativity is smart, but it requires the desire to ask questions and be open to possibilities. It is inspired by the game, but disciplined to an end. Passionate but objective, energetic, but also reflective, individual and collaborative, these are just some of the paradoxes of creative imagination. 


\section{Creative imagination is constructive}

Creative imagination is generative, productive, and open to many alternatives. But in its origin, it seeks to make a difference. The values of creative imagination celebrate and mandate the practical application of its results.

\section{Creative imagination is firm}

It takes a desire to give up certainties and to think expansively; it also requires a strong dose of determination and self-conviction. History demonstrates that new ideas and concepts are often met with apathy, ridiculous or even hostile. That's why courage and creative imagination are linked.

Creative imagination is perceptive

Watching and perception are two different things. The vision is visual and concrete; perception is individual and interpretative. Highly developed individuals have a well-developed ability to perceive things in new ways, to identify patterns and make connections that others can lose.

Creative imagination can be inspired or suppressed

It is necessary to create environments that allow freedom of exploration, exposure to stimuli, and provide the time to reflect, inspire individual and collective imagination. Imaginative thinking can be suppressed by excessive rules and regulations, clogged thinking, stigmatization of failure, hyperfocalization on efficiency and raising conformity over originality.

Creative imagination is naive

Children tend to be less self-conscious than adults, and this natural naivety causes them to ask more questions and think more sideways. Adult experience and expertise may cause them to prematurely close new ways of thinking. Creativity is often served when we "think like a child," anxious about all the reasons why something may not work.

\section{Creative imagination supports ambiguity}

Most human beings accept ambiguity because it makes them uncomfortable. The distinctive sign of a creative thinker is the desire to accept ambiguity, embrace discomfort, and focus on the promise of opportunity rather than hurry back to what is familiar.

Thus, in a narrower context of science aimed at education for the development of creative imagination, based on epistemological indicators (C. Parhomenko, 2014, M. Malhasyan, 2015, L. Turcanu, 2015, O. Arbuz-Spatari, 2013, we present a potential pedagogical concept of education for the development of CISA, which represents a new dimension in the field of education, which through its specific objectives, content and strategies ensures the development of the values of creative imagination in the students' behavior in the perspective of the creative culture (Fig.1). 


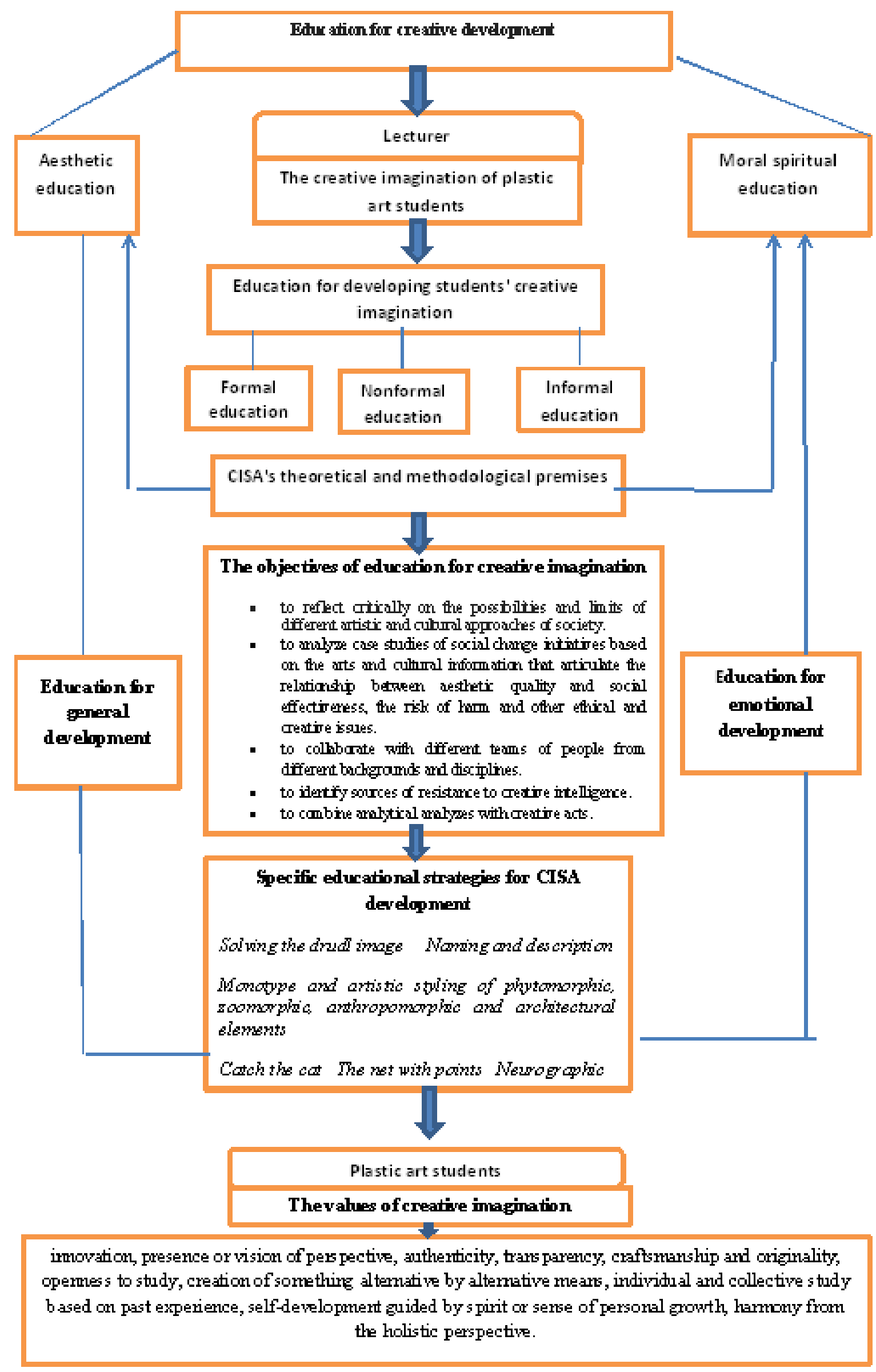

Fig. 1 The pedagogical concept of education for CISA development 
The general objectives of education for the development of creative imagination internationally announced are:

(a) brain creativity and research;

(b) creativity in human sciences by analyzing and researching contexts that encourage creativity (such as the arts) and the contexts that inhibit it (such as social inequality, cultural deprivation, etc.);

(c) creativity and innovation in economy, management, marketing [4].

The aim of education for the development of creative imagination is the formation of creative thinking and aesthetic culture, expressed in the values of creative imagination, through creative competences demonstrating the level of social culture and the level of education of the student.

The specific objectives of education for the development of creative imagination imply the formation of certain attitudes, capacities and knowledge:

- Incorporate into the complex reality of international and multicultural activity, thus better equipping itself for a constantly changing world;

- To break away from the obsolete paradigm of mentality based only on knowledge and orientation towards the most extended - creative, preparing to become strategies of innovation and creativity.

- To seek solutions to the problems identified by cross-cutting policies: social inequalities, injustices, discrimination of creation, cultural and creative deprivation;

- Stimulate the profound re-evaluation of educational purposes and methods, pedagogy and curricula in intellectual, social, cultural and creative fields;

- Have a creative approach in managerial, business and economic contexts that will have a greater impact on the profile environment;

- Use sport (its essentially non-conflictual nature) and performance (its collective way of creation) to promote the spirit of collaboration.

- Engage in the superior research of cognitive sciences, arts, cultural theory.

- To develop and strengthen the teaching of the plastic arts;

- Achieve greater creative qualities in the profile field.

Summarizing on the objectives of developing creative imagination from a pedagogical perspective, we find that creative creativity, creative creativity or pedagogical imagination presupposes the clear and rational application of a set of specific elements, which implies the integration in the deontological attitude of some values of the creative imagination:

- Innovation

- The presence of a vision or dream of perspective;

- Authenticity, transparency, craftsmanship and originality;

- Opening for study;

- Creating something alternative by alternative means;

- Individual and collective study based on past experience;

- Self-development guided by spirituality or the feeling of personal growth;

- Inner harmony from a holistic perspective. 
From the values of the creative imagination it follows that the creative imagination from the pedagogical perspective implies the permanent discipline of the creative forces that are suitable for the students of plastic artists, which ensure: preserving the creative atmosphere in the social relations, maintaining the quality of the creative products within the limits, adjusting their own emotional state, we produce them on the others.

\section{Conclusions}

In the artistic and plastic area, the systematization of higher education presupposes a methodological exigency in the professional training of students artists and teachers through the development of creative imagination from the point of view of the values of creativity.

The artistic knowledge affiliation determines the multifaceted specificity of the professional profiles in the artistic field, it presents objectively their epistemological position and the adaptation of the traditional methodologies: in the general aspect, the nature of the artistic knowledge, and in the particular aspect creative thinking, perception and imagination, creative tangible and spiritual products.

The pedagogical concept of the development of creative imagination determines the pattern of qualities necessary for the lecturer or the teacher in the process of designing and performing the activities efficiently, by capitalizing on his attributes of continuously perfecting the activities specific to the system and the educational process.

But there are ways of educating the creative spirit at the level of higher education. But there is also the need to change the way thinking and the style of realization of the teaching activities presented during the traditional education.

\section{Bibliography}

1. Cosmovici A. Psihologia generală. Iaşi: Ed. Polirom, 1996. 256p.

2. Baciu O.R. Influenţarea formativă a preşcolarilor prin educaţia artisticoplastică Available at: https://documentslide.com/documents/rezumatul-tezei-dedoctorat-5686bf13c180a.html (visited on 06.10.2017 (8:00)

3. Cioca V. Educaţia Artistică-Plastică și Didactica Practică.Disponibil https://documents.tips/documents/educatie-artistico-plastica.html visited on 06.10.2017 (8:20)

4. Herţa D. I., Ciocănel C. Dezvoltarea creativităţii în învăţământ. Revista Interferenţe în educație. Constanța, 2010

Available at: http://asociatia-profesorilor.ro/dezvoltarea-creativitatii-ininvatamant.html (visited on 22.02.2017 10:01)

5. Aims \& Objectives. Available at: https://www.um.edu.mt/emaps/about/aims_-and-_objectives (visited on 20.10.2017(7:53) 